\title{
Configurações
}

Revista de sociologia

EPISTEMOLOGIAS DO SUL: Contextos de Investigação

\section{Entre o passado tradicional e o futuro socialista: as modernidades moçambicanas em Terra Sonâmbula, de Mia Couto}

Between the traditional past and the socialist future: Mozambican modernities in Mia Couto's Terra Sonâmbula (Sleepwalking Land)

Entre le passé traditionnel et le futur socialiste: les modernités mozambicaines dans Terre somnambule de Mia Couto

\section{Kamila Krakowska}

\section{OpenEdition}

\section{Journals}

Edição electrónica

URL: http://journals.openedition.org/configuracoes/2099

DOI: 10.4000/configuracoes.2099

ISSN: 2182-7419

Editora

Centro de Investigação em Ciências Sociais

Edição impressa

Data de publição: 1 Dezembro 2013

Paginação: 167-181

ISBN: 1646-5075

ISSN: 1646-5075

\section{Refêrencia eletrónica}

Kamila Krakowska, «Entre o passado tradicional e o futuro socialista: as modernidades

moçambicanas em Terra Sonâmbula, de Mia Couto », Configurações [Online], 12 | 2013, posto online no dia 18 novembro 2014, consultado o 19 abril 2019. URL : http://journals.openedition.org/ configuracoes/2099; DOI : 10.4000/configuracoes.2099

Este documento foi criado de forma automática no dia 19 Abril 2019.

(c) CICS 


\title{
Entre o passado tradicional e o futuro socialista: as modernidades moçambicanas em Terra Sonâmbula, de Mia Couto
}

\author{
Between the traditional past and the socialist future: Mozambican modernities \\ in Mia Couto's Terra Sonâmbula (Sleepwalking Land) \\ Entre le passé traditionnel et le futur socialiste: les modernités mozambicaines \\ dans Terre somnambule de Mia Couto
}

Kamila Krakowska

1 Terra Sonâmbula, o primeiro romance de Mia Couto, foi lançado em 1992, ano da assinatura do Acordo Geral da Paz que pôs fi m à guerra entre a RENAMO (Resistência Nacional Moçambicana) e o governo da FRELIMO (Frente para a Libertação de Moçambique) que durou dezasseis anos. Esta experiência trágica é o tema marcante da narrativa. O livro abre com a visão da agonia de Moçambique destruído pela guerra civil. "Naquele lugar, a guerra tinha morto a estrada" (Couto, 2008: 11). Esta estrada, que "não se entrecruza com outra nenhuma" e está "mais deitada que os séculos, suportando sozinha toda a distância" (ibid.), torna-se um símbolo daquilo que resta do país.

Este é o cenário de duas narrativas paralelas. A primeira conta a viagem do velho Tuahir e do rapaz traumatizado pela guerra, Muidinga, que se escondem num machimbombo incendiado e ali encontram um diário escrito por Kindzu. A segunda narrativa é composta pelos cadernos que relatam as aventuras de Kindzu, um jovem que deixou a sua casa e embarcou numa viagem tecida de sonhos e estórias para se tornar um guerreiro pela paz, naparama. 0 mito heroico que se vai consolidando nas páginas do romance não é um mito de origens, mas um mito do tempo presente onde as noções de tradição e modernidade precisam de ser repensadas e reformuladas. 
O objetivo deste artigo será analisar como Terra Sonâmbula desconstrói as conotações eurocêntricas destes dois conceitos e questionar o seu papel na formação da nação moçambicana.

4 Tradição e modernidade não são termos antagónicos, mas no pensamento europeu costumavam ser apresentados como binarismos, sendo a modernidade vista como uma característica supostamente intrínseca do mundo ocidental. De facto, Achille Mbembe traça as origens desta oposição na tradição hegeliana e argumenta que, desde então, o discurso filosófico moderno perpetuou a visão, segundo a qual

a distinção entre o Ocidente e as outras fi guras humanas históricas reside, em grande medida, na maneira como o indivíduo se emancipou gradualmente da tutela das tradições e atingiu uma capacidade autónoma de conceber, no presente, a definição das normas e a sua livre fundação pela vontade individual e racional. (Mbembe, 2000: 25) ${ }^{1}$

5 A representação das sociedades não ocidentais como estando sujeitas à autoridade de todo o tipo de dogmas e axiomas que limitam a vontade individual e a racionalidade, tais como a religião, a fé e a tradição, tem profundas implicações metodológicas para o estudo das culturas africanas.

6 Achille Mbembe (2000: 26) e Jean e John Comaroff (1993: xii-xiii) são alguns dos académicos que explicitamente colocam a questão de o conceito de modernidade, que deriva das ideologias ocidentais do progresso universal, poder ser uma ferramenta útil na análise das formas de imaginação cultural, social e política dos africanos. Esta pergunta é crucial para captar todo o leque de limitações e generalizações que o uso deste termo pode induzir. Na sua inspiradora introdução à monografia Modernity and its Malcontents, Jean e John Comaroff enumeram uma série de questões que precisam de ser consideradas:

Como, por exemplo, fazemos jus ao facto de semelhantes forças globais terem conduzido a história colonial e pós-colonial de grandes partes de África, e contudo reconhecemos que foram as condições, conjeturas e indeterminações sociais e culturais específicas que deram a comunidades africanas distintas as suas próprias histórias particulares? Como descrevemos um conjunto de processos dialéticos entre centro e periferia, governante e governado, metrópole e margens, cuja forma é geralmente a mesma, mas cujo conteúdo é frequentemente muito diferente? Como, por outras palavras, escrevemos a antropologia histórica dos sistemasmundo, que não é meramente a História do Sistema-Mundo? Podemos considerar adequadamente os factos mundiais de coerção, violência e exploração coloniais e pós-coloniais sem desprezar o papel de sinais e valores paroquiais, significados locais e sensibilidades históricas? (Comaroff e Comaroff, 1993: xiii) ${ }^{2}$

7 Tomando em consideração todas as advertências perante o perigo de simplificação limitante e empobrecedora das complexas práticas sociais e culturais, modernidade e tradição tornaram-se, porém, referências fundamentais nos discursos de autorrepresentação e autoenunciação dos povos africanos. 0 paradigma de modernidade, como afirma Boaventura de Sousa Santos, "é um projeto sócio-cultural muito amplo, prenhe de contradições e de potencialidades que, na sua matriz, aspira a um equilíbrio entre a regulação social e a emancipação social" (Santos, 1993: 33). No contexto póscolonial africano, o conceito de modernidade continuou a ter uma profunda carga ideológica, mas ao mesmo tempo foi um dos pilares do repensar das identidades das novas nações. Por um lado, existia (e continua a existir) uma expectativa de que as antigas colónias seguissem o modelo de modernidade ocidental frequentemente partilhado pelas sociedades africanas. Por outro lado, as elites dos países recém-independentes procuraram no passado pré-colonial e nas tradições locais o fundamento para a 
identidade nacional. O romance Terra Sonâmbula retrata este movimento bidirecional entre aceitação e rejeição de tradição no processo de construção de identidade nacional no contexto de modernidade.

8 A problematização de tradição e modernidade em Terra Sonâmbula já foi abordada, embora parcialmente, por alguns estudiosos. Ana Mafalda Leite foca a incorporação de intertextos orais na estrutura do romance, uma estratégia narrativa que revela "uma conflitualidade dialógica na tematização das tradições e seu confronto com a modernidade" (Leite, 2003: 45). Identificando e analisando diferentes géneros orais presentes no livro, a estudiosa integra Terra Sonâmbula numa vasta vertente do romance africano que tematiza a tradição e argumenta que "a escolha dos géneros, no caso do escritor moçambicano Mia Couto, funciona como um filtro, como um modelo interpretativo da realidade da sua sociedade, quer no plano temático, quer no formal" ( ibid.: 57).

De facto, a oralidade é um dos principais eixos de interpretação em vários estudos. Gilberto Matusse (1998) vê a incorporação de elementos e motivos característicos para os contos orais, tais como o uso dos provérbios ou o teor didático-moral da narrativa, como uma estratégia de criação de um imaginário moçambicano. Petar Petrov, por seu lado, relaciona a oralidade presente em vários romances de Mia Couto com a "impossibilidade de se assumirem raízes, ligando-as dialeticamente à situação pós-colonial" (Petrov, 2006: 680), enquanto Leonor Simas-Almeida (1995-1996) aborda a dimensão imaginativa e visionária da narrativa oralizada, entre outros. Segundo estes autores, a estrutura não linear de Terra Sonâmbula deriva do seu enraizamento na tradição oral africana. No entanto, na sua tese de doutoramento, Anita Martins de Moraes (2007) propõe uma interpretação alternativa, argumentando que a fragmentação da linearidade discursiva presente no romance deriva do trauma causado pelo conflito armado, e aproxima o livro, cujo trama decorre durante a guerra civil moçambicana, da estética do testemunho.

10 Além disso, o tratamento do tema da oralidade no romance incita a um questionamento da conceptualização pós-colonial do conceito de fronteira que ultrapassa a simples noção de divisão territorial. Phillip Rothwell (2004) demonstra como a oposição rígida entre a escrita e a oralidade fi ca esbatida no romance coutiano, enquanto Ana Margarida Godinho da Fonseca (2006) interpreta a presença do maravilhoso em Terra Sonâmbula como uma expressão do seu enraizamento cultural múltiplo que, justamente, problematiza a formação de identidades fronteiriças.

11 Neste cenário de renegociações identitárias, o oceano parece ser, na opinião de Luís Madureira (2006), um espaço simbólico onde os sonhos da nação podem ser celebrados. Também Ana Mafalda Leite (1998) indica o mar e a ilha como dois espaços axiais na representação da nação moçambicana. No entanto, a imagem de nação narrada neste romance coutiano não é uma utopia onde todos os conflitos sociais possam ser diluídos nas águas do Índico. Neste aspeto, Phillip Rothwell (2004) analisa a personagem do indiano Surendra no contexto do mito da identidade luso-tropical e demonstra as fraturas no seio da nação moçambicana que derivam da hierarquização da sociedade na época colonial. Também Carmen Tindó Secco (2000) afirma que o romance coutiano denuncia a persistência de certos estereótipos raciais e étnicos difundidos pelo regime colonial.

12 Laura Padilha, por seu lado, analisa as epígrafes do romance e o episódio de Muidinga quando lê os cadernos a Tuahir à luz da fogueira, uma cena que inverte os papéis tradicionais do velho contador de histórias e do jovem ouvinte. Na sua opinião, as três 
epígrafes apontam para três universos distintos e, no entanto, relacionados: "Crença dos habitantes de Matimati" demarca o universo africano; "Fala de Tuahir", o universo da experiência pessoal; finalmente, a citação atribuída a Platão refere "o universal" (Padilha, 2002: 35). Esta análise é precedida pelo seguinte comentário:

Vale antes notar [...] ser chegada a hora de se pensarem algumas postulações sem os clichés dualistas que as recobrem e que não contribuem para o avanço dos estudos literários africanos. Assim, ao invés de atribuir à África apenas o peso da tradição oral e do arcaico, deixando para a Europa o papel da modernidade que se associa naturalmente ao universo da escrita, quero-me debruçar sobre a inter-relação de ambas as coisas. Interessa-me o isto $e$ aquilo e, não, o isto ou o aquilo. As produções do pós-75 exigem e clamam pela aditiva, mais que pela alternativa ou exclusiva. ( Ibid.: 34)

13 Esta observação servirá de ponto de partida para a análise da problematização dos conceitos de tradição e modernidade no plano narrativo de Terra Sonâmbula. A iniciática cena da leitura à luz da fogueira acima referida é apenas um dos numerosos exemplos do tratamento deste tema. O papel social e identitário da tradição é frequentemente apresentado no romance através das personagens de velhos: Tuahir, Taímo e o conselho dos anciães da terra de Kindzu. Inicialmente, os mais velhos desempenham o papel de guias de toda a comunidade que conseguem explicar o inexplicável e assegurar a ordem do mundo em que vivem. De facto, no primeiro caderno, intitulado "O tempo em que o mundo tinha a nossa idade" (um título significativo que aponta para um tempo mítico, um tempo de origens), Kindzu relata como o seu pai, Taímo, costumava sonhar e depois contar essas visões noturnas a toda a família. $O$ jovem rapaz às vezes tinha dúvidas "sobre a verdade daquelas visões do velho, estorinhador como ele era" (Couto, 2008: 18), mas apesar de tudo este ritual doméstico de escutar as "notícia[s] do futuro por via dos antepassados" (ibid.) metonimicamente representava o processo de transmissão de sabedoria popular ao longo das gerações. Como afirma Kindzu: "Nesses anos ainda tudo tinha sentido: a razão deste mundo estava num outro mundo inexplicável. Os mais velhos faziam a ponte entre esses dois mundos" (ibid.).

No entanto, este atemporal sistema de ensino e aprendizagem é posto em causa quando o mundo muda dramaticamente. A guerra civil virtualmente aniquila o universo de sabedoria dos mais velhos. As histórias que iam aprendendo com os antepassados já não servem de resposta neste cenário de morte e destruição. Quando Kindzu pede conselho ao grupo dos anciães antes de tomar a decisão de partir em viagem, repara que eles não o conseguem ajudar:

Aquele grupo de idosos, de repente, me pareceu estar perdido também. Já não eram sábios mas crianças desorientadas. Mais que ninguém, eles sofriam a visão da terra em agonia. Cada casa destruída tombava em ruínas dentro de seus corações. As mãos do professor sangravam dentro do peito dos mais velhos. Aquela guerra não se parecia com nenhuma outra que tinham ouvido falar. Aquela desordem não tinha nenhuma comparação, nem com as antigas lutas em que se roubavam escravos para serem vendidos na costa. (Ibid.: 33)

Será que Terra Sonâmbula proclama deste modo o simbólico fim da tradição enquanto elemento constitutivo da vida comunitária? A imagem dos sábios que se transformam em "crianças desorientadas" (ibid.) poderia sugerir que a tradição não é compatível com o mundo moderno. No entanto, esta interpretação Superficial de uma cena isolada apenas retomaria o pressuposto eurocêntrico de que a tradição é intrinsecamente imutável. Segundo discute Terence Ranger no estudo sobre a visão estereotipada dos povos africanos pelos colonizadores europeus, os costumes africanos valorizavam o passado 
coletivo, mas nunca eram estáticos (Ranger, 1983: 247). A ideia de que as tradições precisam de ser profundamente ritualizadas e inflexíveis nasce quando do surgimento da vaga dos nacionalismos europeus no século XIX. Nesta época, os povos europeus redefiniram as suas identidades e procuraram uma âncora que os ligasse às suas origens. De acordo com Eric Hobsbawm (1983), como consequência desses nacionalismos surgiram numerosas tradições inventadas que suportaram (e continuam a suportar) essas novas narrativas nacionais.

Em Terra Sonâmbula, os mais velhos da terra não conseguem ajudar Kindzu, não porque a tradição em si mesma tenha perdido o seu valor na realidade contemporânea, mas porque esses velhos sábios são incapazes de procurar novas coordenadas num mundo onde a guerra destruiu as bússolas. 0 único conselho que podiam dar era consultar o nganga, o adivinho. No entanto, Kindzu tinha de evitar o tema dos naparamas, porque o curandeiro "se iria sentir magoado de não saber mexer em [seus] pedidos" (Couto, 2008: 34). Assim, esse grupo dos anciães representa o passado supostamente imutável e estático das tradições inventadas e ritualizadas. 0 seu mundo, tal como o mundo dos nacionalistas românticos europeus, é um mundo imaginário que se desmorona quando confrontado com uma realidade em constante transformação. Em contraste, Taímo e Tuahir, os velhos guias/seguidores de Kindzu e Muidinga respetivamente, são viajantes que vão recriando as tradições.

Tuahir é, sem dúvida, um guia protetor de Muidinga. É ele quem ativamente procura novos caminhos, decide abandonar o autocarro incendiado e inclusive ajuda o seu antigo colega Nhatamaca a cavar um rio. 0 capítulo "O fazedor de rios" é muito significativo para a caracterização de Tuahir. 0 velho argumenta sobre a sua decisão de colaborar no aparentemente louco plano de Nhatamaca: "Em vez de esperarmos na estrada, fazemos o nosso caminho" (ibid.: 97). Em contraste com os anciães da vila de Kindzu, que parecem crianças desorientadas e abatidas, Tuahir é comparado com animais - aves e felinos - que seguem em frente na procura de alimentos e de abrigo, experientes e esquivos nas suas deslocações (ibid.: 93-94). A postura do velho que guia Muidinga pelo mato e lhe dá conselhos sobre relações amorosas (uma espécie de viagem iniciática) demonstra a importância da transmissão da sabedoria entre as gerações. No entanto, uma das lições de Tuahir é justamente a de criar o próprio caminho, de procurar saídas, de experimentar novas soluções. Esta atitude de abertura para o futuro e para a aprendizagem sem renunciar à tradição é simbolicamente representada na estrutura do capítulo: o episódio abre com Tuahir a falar com Muidinga sobre as mulheres e fecha com o seu pedido para que Muidinga conte mais estórias do "fi damãe desse Kindzu" que "já vive quase connosco" (ibid: 99). Assim, tanto o velho como a criança vão narrando as suas experiências e aprendendo um com o outro.

18 Taímo, o pai de Kindzu, é uma personagem muito complexa do ponto de vista da perceção do papel de tradição na sociedade africana contemporânea. Por um lado, ele parece invocar o carácter ritualizado das tradições. $O$ fantasma do velho tenta impedir a viagem de Kindzu porque receia que, com a partida do filho, ninguém lhe vá prestar as devidas cerimónias. No entanto, as suas razões são muito mais profundas. $O$ velho explica ao filho porque a desejada viagem não poderia trazer a paz de espírito que Kindzu procurava:

O velho Taímo se explicou: eu não podia alcançar nada do sonhado enquanto a sombra dele me pesasse. A mesma coisa se passava com a nossa terra, em divórcio com os antepassados. Eu e a terra sofríamos de igual castigo. (Ibid.: 48) 
19 A impossibilidade de alcançar o sonho enquanto o sujeito está "em divórcio com os antepassados" não é um chamamento para seguir cegamente as tradições sem refletir sobre o seu significado, o seu valor cultural e identitário, no mundo atual. Pelo contrário, as palavras do velho são, de facto, um chamamento para repensar o papel e o lugar da tradição na construção das nações africanas pós-coloniais. O castigo que Kindzu e "a terra", isto é, o povo moçambicano, sofrem é uma dor existencial de uma comunidade que ainda está em vias de definir as suas origens, os seus laços de pertença, a sua história. Taímo, que viu na independência de Moçambique "a consumação de todos seus sonhos" ( ibid.: 18), não trava o caminho de Kindzu, mas antecipa os desafios e os perigos que o esperam no processo de forjar a sua identidade enquanto indivíduo e enquanto moçambicano.

20 A personagem Taímo parece representar o drama de consciência que Abiola Irele identifica na produção literária africana nos períodos de libertação e pós-independência. Como argumenta o crítico nigeriano, a tradição é um grande eixo temático da literatura africana pós-colonial, influenciando tanto o plano narrativo como a construção formal das obras. Inicialmente, esta reivindicação estética (que Irele denomina de "tradicionalismo estético") é ideologicamente muito marcada, visto que as elites dos países recém-nascidos procuravam nos registos pré-coloniais os alicerces duma identidade nacional unificadora (Irele, 2001: 57). No entanto, a ideia de nação e de identidade nacional fundamentada exclusivamente a partir da tradição não consegue conceber um sentido de integridade identitária:

Há, porém, um reverso lamentável desta atividade ideológica, um drama de consciência que o tom do discurso nacionalista africano não consegue dissimular apesar da sua vigorosa orientação para os objetivos políticos. Visto que o apelo à tradição no nacionalismo cultural não é uma simples retórica de autojustificação, ele é baseado numa visão subjetiva fortemente consolidada, no sentido de uma identidade formada e interrompida pelas imposições culturais europeias. Sentiu-se, então, uma necessidade de estabelecer uma reconexão com aquela identidade para devolver ao africano a integridade do ser e da consciência. (Irele, 2001: 53) ${ }^{3}$

o discurso nacionalista vigente em Moçambique no período de pós-independência foi profundamente marcado pelo drama de consciência de que fala Abiola Irele. A situação política deste país africano moldou o projeto nacionalista propagado pela FRELIMO e, necessariamente, influenciou também a maneira como foi visto o papel da tradição na sociedade moçambicana. Por um lado, as elites precisavam de redefinir o imaginário nacional e buscavam referências identitárias no passado pré-colonial, por exemplo atribuindo o estatuto de herói nacional ao último imperador de Gaza, Ngungunhane ${ }^{4}$. Por outro lado, Moçambique é um país culturalmente e etnicamente heterogéneo, pelo que os governantes temiam o surgimento de conflitos internos caso as várias comunidades se identificassem apenas com a sua tribo. Além disso, já nos primeiros anos da luta de libertação, surgiu uma divisão forte entre dois planos de identidade e oposição anticolonial: um de matriz rural e tradicionalista, representado pelos chefes tribais, e outro de carácter urbano e "modernista", da FRELIMO. Como relata o estudioso moçambicano José Luís Cabaço, o conflito entre estes dois grupos aprofundou ainda mais a polarização existente desde os tempos coloniais entre os conceitos de "modernidade" e "tradição":

O poder tradicional foi acusado de representar um obstáculo à acção anti-colonial unitária e de se "opor à ciência e à técnica", preconizando meios e práticas insuficientes para fazer frente ao poder colonial. Enfim, o poder tradicional é, a 
partir de então, estigmatizado pelos jovens combatentes como uma parte do aparelho do poder colonial - a que havia assegurado a ligação com as populações rurais - e, de consequência, um dos alvos da luta ideológica do movimento nacionalista. A FRELIMO procedeu, na sua elaboração teórica, a uma verdadeira "dissecação" da componente tradicional. Por um lado, condenou as suas instituições políticas e religiosas e, em geral, os sistemas de organização da vida social. Por outro lado, o movimento valorizava os sistemas de produção e troca e de parentesco assim como as manifestações de carácter artístico e cultural. Esta postura selectiva e autoritária prolongar-se-ia após a independência por mais de uma década clandestinizando - e portanto retardando - o diálogo e a negociação entre o pólo "modernista" e o pólo "tradicionalista" da sociedade. (Cabaço, 2004: 243)

Por isso, a FRELIMO procurou não só modernizar o seu país, mas também relacionar o seu projeto nacionalista com uma visão de modernidade enraizada na ideologia marxista. Como argumenta Patrick Chabal, na Europa o desenvolvimento do nacionalismo entendido como uma ideologia política foi uma consequência do processo de modernização da economia. Em África, pelo contrário, as elites dos recém-surgidos Estados independentes pretendiam modernizar o seu país a partir de reformas políticas de cariz nacionalista:

Na Europa a reforma política foi o resultado das dinâmicas económicas; e África ela pretendia ser o seu motor. Assim, o projeto nacionalista africano incorporou a visão de modernidade derivada da experiência europeia; a sua suposição central foi que a criação do estado-nação africano independente levaria à modernidade de tipo europeu. Neste sentido, a chegada da independência significou a transferência da "modernidade imaginada" projetada pela Europa. Mas, de facto, esta expectativa não podia ser cumprida, embora as elites nacionalistas tivessem afirmado suportála quando consolidavam o poder político. Com a passagem do tempo, as consequências da sedimentação das políticas pós-coloniais combinadas com a incapacidade do Estado de produzir os benefícios económicos concretos da modernidade levaram a questionar essas suposições. Ou melhor, isto desencadeou a re-avaliação em todos os níveis da sociedade do que a modernidade poderia significar no contexto pós-colonial. (Chabal, 2008: 45)

No caso de Moçambique pós-independência, esta "modernidade imaginada" foi derivada diretamente do modelo soviético. Embora os seus pressupostos económicos sejam distintos da modernidade de tipo europeu de que fala Chabal, pode-se observar aqui o mesmo tipo de vínculo simbólico entre o discurso da modernidade e o nacionalismo oficial. A criação da nova ordem social e do novo homem moçambicano passou a ser um imperativo na construção do independente e moderno estado-nação.

Os livros de Mia Couto frequentemente questionam este discurso de nacionalismo moderno e/ou de modernidade nacionalista que facilmente pode ser distorcido e aproveitado pelas elites locais para assegurar o seu poder político. O Último Voo do Flamingo e A Varanda do Frangipani são excelentes exemplos do re-pensamento crítico do quadro político-social de Moçambique pós-colonial.

Em Terra Sonâmbula, a viagem de Kindzu representa simbolicamente o percurso pelos modelos de modernidade que surgem em Moçambique após a independência. $O$ protagonista parte da sua terra natal, onde a tradição é vista como uma âncora identitária, fixa e imutável nos tempos contemporâneos, e chega a Matimati, uma vila administrada pelo socialista Estêvão Jonas. Este funcionário da autoridade local aproveita o seu poder para obter lucros financeiros e usa o discurso socialista misturado com elementos de crenças e preconceitos populares para garantir a sua segurança. Logo à sua chegada, Kindzu é avisado pelos moradores de que deve desconfiar das autoridades 
porque podem prendê-lo "espontânea e imediatamente" (Couto, 2008: 60). No entanto, ninguém se atreve a explicar os recentes acontecimentos (um navio abastecido naufragou perto da vila, mas as condições meteorológicas aparentemente não permitiam buscar a carga com segurança), e os habitantes chamam o antigo secretário do administrador para "trazer uma autorizada versão do acontecido" (ibid.). A expressão "uma autorizada versão" denuncia à partida que a história contada por Assane será apenas uma estória que representa a visão do acontecido segundo os desejos dos governantes e não a realidade em si. De facto, a narrativa que se segue é intercalada com os clichés linguísticos típicos do discurso socialista, tais como "o inimigo do povo", "o comício público" ou "massas populares" (ibid.: 60-61). No entanto, estas expressões ritualizadas são utilizadas pelo secretário em contextos inesperados e ilógicos. Ao recontar o seu testemunho "deixando intactos os modos oficiais de seu falar" (ibid:: 60), Kindzu-narrador acaba por parodiar os discursos políticos daquele período, destacando a irrepresentatividade da linguagem politicizada.

Segundo o seu relato, o naufrágio foi causado por "uma tempestade furiosa e nãoplanificada, da qual resultara a perda de sentidos da lua e a implementação de total escuridão generalizada" (ibid.). $\mathrm{O}$ uso do substantivo "implementação" e do adjetivo "nãoplanifi cado" para descrever um fenómeno natural e as suas consequências visa criar a impressão de que as autoridades são capazes de controlar a situação atual do país e de assegurar o seu futuro bem-estar. No entanto, para que tal aconteça, é urgente combater "o inimigo do povo" (ibid.), supostamente o único culpado das falhas do governo. Este tipo de argumentação, por mais irracional que seja, foi (e ainda é) frequentemente usado pelas ditaduras e pelos Estados que adotaram o regime de partido único, entre os quais a União Soviética e os respetivos países-satélite. Segundo o linguista Michał Głowiński, que analisou o fenómeno da "Novafala" na Polónia comunista, este tipo de discurso pode ser considerado uma quasi-língua porque é uma retórica que influencia todos os níveis da linguagem, desde a fonética até à sintaxe (Głowiński, 2009: 11-33). O seu objetivo não é a comunicação de uma mensagem concreta, mas a transmissão de uma ideologia. Por isso, é comum o uso arbitrário de expressões fixas e clichés rearticuláveis.

Em Terra Sonâmbula, a acumulação de fraseologia socialista típica conduz à hipérbole, que por sua vez concebe um tom fortemente irónico. Além disso, o claro distanciamento do narrador, que apenas relata esta "versão autorizada" dos acontecimentos, incita o leitor ao exercício de desconstrução crítica da imagem do mundo apresentada pelas autoridades de Matimati. o discurso - usado e abusado para fins políticos no período pósindependência - "constitui um fértil terreno para o exercício do poder" (Can, 2012: 242), como argumenta Nazir Can na sua análise dos comícios públicos nos romances de um outro escritor moçambicano, João Paulo Borges Coelho.

No romance coutiano, um elemento recorrente e muito significativo deste exercício do poder através da linguagem é a criação de uma forte oposição entre as populações locais e os governantes que, de facto, reproduz as relações de poder colonial. As palavras do administrador Jonas Estêvão proferidas durante o "comício bastante público" (Couto, 2008: 60) revelam a sua atitude paternalista perante os habitantes de Matimati:

- Às vezes quase desisto de vocês, as massas populares. Penso: não vale pena, é como pedir a um cajueiro para não entortar seus ramos. Mas nós cumprimos destino de tapete: a História há-de limpar os pés nas nossas costas. (Ibid.: 61)

Esta passagem demonstra a clara distinção entre "nós" (os funcionários do aparato do Estado) e "vocês" (as massas populares), sendo que os últimos são vistos como uma 
unidade abstrata e uniforme que não tem vontade própria e precisa de ser instruída pelos administradores. Esta falta de caracterização individualizada e individualizante da população local evoca a representação do Outro nas narrativas da época dos Descobrimentos. Segundo a análise de Nicholas Thomas, esses textos apenas asseguravam o carácter universal dos valores europeus e não descreviam o "Outro" enquanto indivíduo (Thomas, 1994: 71). Além disso, a referência ao cumprimento de um dever moral, apesar da resistência passiva dos "locais", evoca os objetivos evangélicos e civilizacionais dos colonizadores que pretendiam impor a sua visão do mundo e os seus paradigmas culturais aos povos subjugados. De facto, Estêvão Jonas considera as manifestações culturais enraizadas nas crenças e tradições locais como "obscurantistas" (Couto, 2008: 61) e inclusive proíbe as danças e cerimónias que acompanhavam os pedidos dirigidos aos antepassados "para outros navios se afundarem, suas cargas se espalharem e desaguarem nas mãos dos famintos" (ibid.).

O desrespeito pela mundividência dos diversos grupos étnicos e culturais que habitam o território de Moçambique, e que se destaca nas passagens acima citadas, deriva diretamente de uma visão de modernidade empobrecedora e limitadora, segundo a qual a modernidade é erroneamente considerada um termo antagónico da tradição. Phillip Rothwell descreve de forma sucinta as políticas de unificação nacional e, em consequência, de aniquilação das diferenças tribais levadas a cabo pela FRELIMO nos primeiros anos da independência:

O governo veementemente desencorajou qualquer manifestação da identidade tribal, adotando o português como a língua da unidade nacional. Além disso, comunidades inteiras que há séculos viviam no campo foram obrigatoriamente deslocadas para as aldeias agrícolas "para o seu próprio bem". De facto, quase dois milhões de moçambicanos foram afetados por esta política, que era desconfortavelmente similar à tática usada pelo regime colonial português nos seus últimos dias para controlar a população rural. A FRELIMO justificou-a como um instrumento para prevenir mortes em caso de inundações cíclicas que ocorrem em algumas partes do país e como uma maneira mais eficiente de produzir alimentos para o proletariado. Infelizmente, isso arrasou os costumes locais e foi uma nova forma de as práticas indígenas serem alvo das ideologias europeias, inflexivelmente aplicadas. (Rothwell, 2004: 23)

31 A comparação que Rothwell estabelece entre as táticas da FRELIMO e as do regime colonial é crucial para compreender que a adoção irrefletida e inflexível de qualquer ideologia ou visão política, tal como a ideia de modernidade marxista, é lesiva tanto para os cidadãos como para o próprio projeto nacionalista.

No seu estimulante livro Novos Combates pela Mentalidade Sociológica, o sociólogo moçambicano Carlos Serra analisa as premissas e as consequências do utópico projeto unifi cador da FRELIMO:

O regime insiste demoradamente sobre a necessidade de "escangalhar" o aparelho de Estado colonial. Mas, na verdade, surge um Estado muito mais possante ou, melhor dito, um Estado-Partido tentacular, gestor de uma modernidade autoritária, controlando um pouco de tudo por todo o lado: "nível de consciência revolucionária", preços, mercadorias, lojas, reassentamento rural, confissões religiosas, etc. O que na prática acontece não é que o Estado colonial tenha sido abolido, mas que ele tenha sido politicamente sobrevalorizado. (Serra, 1997: 100)

Serra conclui a sua argumentação demonstrando como este tipo de políticas nacionalistas enraizadas numa visão de modernidade autoritária desencadeou um processo de fraturação da sociedade: 
Daí um possante maniqueísmo diariamente reactivado, uma espécie de bipolaridade eu de, de "cissiparidade" revolucionária permanente, uma constante "diabolização" dos inimigos da mudança presente em todos os actos da revolução, nos discursos, nos programas, nos julgamentos, nas punições públicas, enfim nesse acto maciço que era a confissão partidária ou pública, fenómeno ao mesmo tempo uno e plural que acabou por ganhar um cunho popular. A sigla é simples: quem não está connosco, está contra nós. (Ibid.: 101-102) políticos e os antigos opressores culmina no episódio em que Estêvão Jonas decide colaborar com o fantasma do colono Romão Pinto. Sozinho, o administrador - ou "administraidor" como o chama a esposa (Couto, 2008: 183) - conseguia arranjar uns "negócios de tigela furada, coisa de pouco brilho" (ibid.: 181). Juntos, seguindo as indicações do português falecido, teriam a verdadeira oportunidade de enriquecer. Esta traição dos ideais que Estêvão deveria defender não se deve apenas à sua ganância e falha de moral, mas tem razões muito mais profundas. Como revela a sua mulher Carolinda, o administrador "era hoje um homem de mando, amanhã seria um pau-mandado" (ibid.: 186), e era frustrado porque se sentia preso em Matimati onde "não entendia a língua nem os costumes daquela gente" (ibid.). O percurso deste homem "mortiço, acanhado de sonhar, medroso de pensar [...] cansado de sua militância, exausto por sempre ter que se apagar" (ibid.: 187) demonstra que o projeto nacionalista do governo moçambicano dos primórdios da independência não conseguiu criar o desejado sentido de identidade e unidade.

No entanto, é importante notar que a fi gura de Estêvão Jonas, o representante do poder político urbano centralizado, e o conselho dos anciães da aldeia de Kindzu, que representam a autoridade local, são, de facto, duas faces do mesmo aparelho do Estado. Como argumenta Mahmood Mamdani, estes dois modos alternativos de controlo derivam do modelo de governação colonial (cf. Mamdani, 1996: 18). Ali, a necessidade de garantir uma colonização eficiente tornou indispensável encontrar algum modo de incorporar as populações nativas dentro da estrutura de poder. Em consequência, houve uma bifurcação do sistema de governação, que Mamdani descreve usando a metáfora da face dupla de Janus (ibid.). o primeiro sistema, direto e essencialmente urbano, assegurava os direitos sociais e legais dos cidadãos, excluindo os nativos das malhas da sociedade civil. 0 segundo, indireto e rural, era baseado na autoridade tribal que impunha a preservação da ordem social recorrendo ao poder de tradição e costume.

Em conclusão, as andanças de Kindzu pelas terras de Moçambique de pós-independência desencadeiam uma viagem pelos diferentes paradigmas de modernidade e tradição do novo estado-nação vigentes naquela altura. Desconstruindo tanto a visão tradicionalista do mundo que exclui qualquer possibilidade de mudança como o projeto nacionalista fundado em ideologias políticas sem respeito pela herança cultural e identitária dos vários povos moçambicanos, Terra Sonâmbula desafia o erróneo binarismo entre tradição e modernidade. 0 romance parece clamar pelo repensamento da própria ideia de nação moçambicana porque as "ideias, todos sabemos, não nascem nas cabeças das pessoas", mas começam "num qualquer lado, são fumos soltos, tresvairados, rodando à procura de uma devida mente" (Couto, 2008: 46). Este ditado de Kindzu, que evoca a famosa "Teoria Itinerante" de Edward Said (1983; 2005), demonstra, por um lado, a necessidade de abertura e de aprendizagem. Por outro lado, esses "fumos soltos" de pensamento precisam de ser moldados e adaptados ao contexto local porque só as viagens 
transformativas podem revelar todo o potencial de uma teoria (a de Said) ou, neste caso, de um projeto nacionalista.

\section{BIBLIOGRAPHY}

CABAÇO, José Luís (2004), “Identidades, conflito e liberdade”, Travessias, n.ำ 4/5, 237-250.

CAN, Nazir Ahmed (2012), "Castelos de cartas marcadas: o discurso público da elite política nos romances de João Paulo Borges Coelho", in Ana Mafalda Leite et al. (org.), Nação e Narrativa Póscolonial I, Angola e Moçambique: Ensaios. Lisboa: Colibri, 229-244.

CHABAL, Patrick (2008), "Imagined modernities: Community, nation and state in postcolonial Africa”, in Luís Reis Torgal, Fernando Tavares Pimenta, Julião Soares Sousa (org.), Comunidades Imaginadas: Nação e nacionalismos em África. Coimbra: Imprensa da Universidade de Coimbra, 41-48. COMAROFF, Jean e COMAROFF, John (1993), “Introduction”, in Jean Comaroff e John Comaroff (ed.), Modernity and its Malcontents. Ritual and power in Postcolonial Africa. Chicago: University of Chicago Press, xi-xxxv.

COUTO, Mia (2008), Terra Sonâmbula. Lisboa: Caminho.

FONSECA, Ana Margarida Godinho da (2006), Percursos da Identidade. Representações de nação na literatura pós-colonial de língua portuguesa, Tese de Doutoramento. Lisboa: Faculdade de Letras, Universidade de Lisboa.

GŁOWIŃSKI, Michał (2009), Nowomowa i CiĄgi Dalsze: Szkice Dawne i Nowe. Kraków: Universitas. HOBSBAWM, Eric (1983), "Introduction: Inventing traditions”, in Eric Hobsbawm \& Terence Ranger, The Invention of Tradition. Cambridge: Cambridge University Press, 1-14.

IRELE, Abiola (2001), The African Imagination: Literature in Africa and the diaspora. Oxford: Oxford Univeristy Press.

LEITE, Ana Mafalda (2003), Literaturas Africanas e Formulações Pós-coloniais. Lisboa: Colibri.

LEITE, Ana Mafalda (1998), Oralidades e Escritas nas Literaturas Africanas. Lisboa: Colibri.

MADUREIRA, Luís (2006), Imaginary Geographies in Portuguese and Lusophone-African Literature: Narratives of discovery and empire. Lewiston: Edwin Mellen Press.

MAMDANI, Mahmood (1996), Citizen and Subject. Contemporary Africa and the legacy of late colonialism. Princeton: Princeton University Press.

MATUSSE, Gilberto (1998), A Construção da Imagem de Moçambicanidade em José Craveirinha, Mia Couto e Ungulani Ba Ka Khosa. Maputo: Livraria Universitária da Universidade Eduardo Mondlane.

MBEMBE, Achille (2000), De la postcolonie. Essai sur l'imagination politique dans l'Afrique contemporaine . Paris: Karthala.

MORAES, Anita Martins Rodrigues de (2007), O Inconsciente Teórico: Investigando estratégias interpretativas de Terra Sonâmbula, de Mia Couto, Tese de Doutoramento. Campinas, SP: Universidade Estadual de Campinas. 
PADILHA, Laura Cavalcante (2002), Novos Pactos, Outras Ficções. Ensaios sobre literaturas afro-lusobrasileiras. Lisboa: Novo Imbondeiro.

PETROV, Petar (2006), “O universo romanesco de Mia Couto”, in Pires Laranjeira, Maria João Simões e Lola Geraldes Xavier (org.), Estudos de Literaturas Africanas. Cinco povos, Cinco nações, Atas do Congresso Internacional de Literaturas Africanas de Língua Portuguesa, Coimbra, 2003. Coimbra: Novo Imbondeiro, 672-681.

RANGER, Terence (1983), "The invention of tradition in colonial Africa”, in Eric Hobsbawm \& Terence Ranger (org.), The Invention of Tradition. Cambridge: Cambridge University Press, 211-262.

ROTHWELL, Phillip (2004), A Postmodern Nationalist: Truth, orality and gender in the work of Mia Couto. Lewisburg: Bucknell University Press.

SAID, Edward (2005), "Reconsiderando a teoria itinerante", in Manuela Ribeiro Sanches (org.), Deslocalizar a "Europa": Antropologia, arte, literatura e história na pós-colonialidade. Lisboa: Cotovia, 25-42.

SAID, Edward (1983), The World, the Text and the Critic. Cambridge: Harvard University Press.

SANTOS, Boaventura de Sousa (1993), "Modernidade, identidade e a cultura de fronteira", Tempo Social, 5(1-2), 31-52.

SECCO, Carmen Lucia Tindó (2000), "Mia Couto e a 'incurável doença de sonhar”, in Maria do Carmo Sepúlveda e Maria Teresa Salgado (org.), África \& Brasil: Letras em laços. Rio de Janeiro: Atlântica, 161-286.

SERRA, Carlos (1997), Novos Combates pela Mente Sociológica. Sociologia política das relações de poder em Moçambique. Maputo: Livraria Universitária da Universidade Eduardo Mondlane.

SIMAS-ALMEIDA, Leonor, (1995-1996), “A redenção pela palavra em Terra Sonâmbula de Mia Couto”, Revista da Faculdade de Letras - Universidade de Lisboa, n. 19-20, 159-169.

THOMAS, Nicholas (1994), Colonialism's Culture: Anthropology, travel and government. Cambridge: Polity Press.

\section{NOTES}

1. “... la distinction entre l'Occident et les autres fi gures humaines historiques résiderait, dans une large mesure, dans la manière dont l'individu s'y serait progressivement émancipé de la tutelle des traditions et aurait atteint une capacité autonome à concevoir, dans le présent, la définition des normes et leur libre fondation par des volontés individuelles et rationnelles" (Mbembe, 2000: 25). [Tradução da autora.]

2. "How, for instance, do we do justice to the fact that similar global forces have driven the colonial and postcolonial history of large parts of Africa, and yet recognize that specifi c social and cultural conditions, conjunctures, and indeterminacies have imparted to distinct African communities their own particular histories? How do we describe a set of dialectical processes between center and periphery, ruler and ruled, metropole and margins, whose form is broadly the same but whose content is often very different? How, in other words, do we write a historical anthropology of world systems that is not merely the History of the World System? Can we take sufficient account of the worldwide facts of colonial and postcolonial coercion, violence, and exploitation, yet not slight the role of parochial signs and values, local meanings and historical sensibilities?". [Tradução da autora.] 
3. "There is, however, a pathetic underside to all of this ideological activity, a drama of consciousness that the tone of African nationalist discourse is unable to conceal despite its vigorous orientation toward political objectives. For the appeal to tradition in cultural nationalism is not a mere rhetorical mode of self-justification; it rests on a firmly entrenched subjective disposition, the sense of a constituted identity disrupted by the cultural impositions of Europe. There was, thus, a felt need to make a reconnection to this identity in order to restore the African to an integrity of being and consciousness." [Tradução da autora.]

4. Ngungunhane (1850?-1906) foi o último imperador de Gaza, atualmente o território de Moçambique. Capturado em 1895 por Joaquim Mouzinho de Albuquerque, foi condenado ao exílio nos Açores. O monarca subiu ao trono em 1884, eliminando o herdeiro legítimo, e conseguiu durante o seu reinado estender as posses do império. Para a FRELIMO, Ngungunhane, que não aceitava a soberania portuguesa e enfrentou o seu exército, tornou-se um símbolo da luta anticolonial. No entanto, este mito foi posto em causa em algumas obras literárias pós-coloniais, entre as quais Ualalapi, de Ungulani Ba Ka Khosa, o conto "Quem Manda Aqui?" da coletânea As Andorinhas, de Paulina Chiziane, ou Os Ossos de Ngungunhana, João Kuimba, Chico Ndaenda e Outros Contos, de Marcelo Panguana.

5. "In Europe political reform was the outcome of economic dynamics; in Africa it was intended to be its driving force. Thus, the African nationalist project embodied a vision of modernity that was derived from the European experience; its core assumption was that the creation of the independent African nation-state would deliver European-type modernity. In that sense the coming of independence was the transfer of the 'imagined modernity' projected by Europe. But in truth, this expectation could not be met, although the nationalist elites claimed to uphold it whilst they set about consolidating political control. Over time, the consequences of the sedimentation of post-colonial politics and the state's inability to deliver on the concrete economic benefits of modernity combined to challenge such assumptions. Or rather, it triggered the re-assessment at all levels of society of what modernity might entail in the post-colonial context." [Tradução da autora.]

6. "The government vehemently discouraged any show of tribal identity, adopting Portuguese as the language of national unity. Additionally, whole communities that have lived for centuries in rural backwaters were compulsorily relocated to farming villages "for their own good". In fact, nearly two million Mozambicans were affected by this policy, which was uncomfortably similar to a tactic used by the Portuguese colonial regime in its dying days to maintain control over the rural population. Frelimo explained villagization as a tool to prevent loss of life in the event of cyclical fl ooding that occurs in parts of the country, and as a more efficient way of producing food for the needs of the proletariat. Unfortunately, it rode roughshod over local customs, and was a new way in which European ideologies targeted indigenous practice, and were inflexibly applied." [Tradução da autora.]

\section{ABSTRACTS}

Em 1992 o escritor moçambicano Mia Couto publicou o seu primeiro romance, Terra Sonâmbula. No decorrer da narrativa, as personagens vão vivenciando episódios que simbolizam diferentes paradigmas de modernidade que este país africano seguiu no pós-independência. 0 objetivo do presente artigo é discutir como o livro desconstrói vários pressupostos e estereótipos relacionados com os conceitos de tradição e modernidade, frequentemente apresentados como 
binarismos. Além disso, será analisado o seu papel na construção de Moçambique enquanto nação.

In 1992, the Mozambican writer Mia Couto published his fi rst novel Sleepwalking Land. In the course of the narrative, the characters live through episodes symbolizing different paradigms of modernity which this African country followed in the post-independence period. This article discusses how the book deconstructs a number of assumptions and stereotypes related to the concepts of tradition and modernity, often presented as binarisms. Furthermore, their role in the construction of Mozambique as a nation is analyzed.

En 1992, l'écrivain mozambicain Mia Couto a publié son premier roman Terre somnambule. Durant le récit, les personnages font l'expérience d'épisodes qui symbolisent des différents paradigme de modernité que ce pays africain a suivi lors de l' après-indépendance. Le but de cet article est de discuter la forme dont le livre déconstruit les nombreuses hypothèses et les stéréotypes liés aux notions de tradition et de modernité, souvent présentés comme des binarismes. Il sera en outre examiné leur rôle dans la construction du Mozambique comme nation.

\section{INDEX}

Mots-clés: Tradition, modernité, l'après-indépendance, Mia Couto, Terre somnambule

Palavras-chave: Tradição, modernidade, pós-independência, Terra Sonâmbula

Keywords: modernity, post-independence, Sleepwalking Land

\section{AUTHOR}

\section{KAMILA KRAKOWSKA}

Universidade de Coimbra/CESA/Universidade de Lisboa

krakowska.rodrigues@gmail.com 